that gives sequential information about peak patterns within utterances, in contrast to the present one which gives nonsequential summary data for the entire sample of speech analyzed.

In conclusion, we feel that the Voxcom system offers a reliable means for doing real-time acoustic analysis of human speech. Its features make it suitable for a number of applications involving voice data which are not limited to clinical research.

\section{REFERENCE}

AlPERT, M. (1982). Encoding of feelings in voice. In P. J. Clayton \& J. E. Barrett (Eds.), Treatment of depression: Old controversies and new approaches (pp. 217-227). New York: Raven Press.

\title{
ANNOUNCEMENT \\ Eleventh Annual Conference on Language Development \\ October 17, 18, and 19, 1986
}

The Boston University School of Education invites papers for the 11th Annual Conference on Language Development, to be held on October 17, 18, and 19, 1986.

Papers on the topics of first and second language acquisition, bilingualism, language disorders, writing, literacy, narratives, ASL and sign language, neurolinguistics, sociolinguistics, theoretical language acquisition, and universal grammar will be considered for presentation at the conference. The deadline for submission of abstracts is June 1, 1986. This year's keynote speaker is Noam Chomsky from the Massachusetts Institute of Technology.

For more information write: Language Development Conference, School of Education, Boston University, Boston, MA 02215. 